\title{
MTHFR (C677T, A1298C) and MTRR (A66G) polymorphisms associated with the risk of megaloblastic anemia in China
}

\section{Jihong Zhang ( $\square$ zhangjh96615@126.com )}

Shengjing Hospital of China Medical University https://orcid.org/0000-0002-5921-2417

Shaokun Wang

Shengjing Hospital of China Medical University

Research article

Keywords: MTHFR, MTRR, polymorphisms, megaloblastic anemia

Posted Date: September 16th, 2019

DOI: https://doi.org/10.21203/rs.2.14459/v1

License: (c) (1) This work is licensed under a Creative Commons Attribution 4.0 International License. Read Full License 


\section{Abstract}

Purpose MTHFR (C677T and A1298C) and MTRR (A66G) polymorphisms have been reported to be associated with the increased risk of cardiovascular diseases, pregnancy complications, and neural tube defects, except megaloblastic anemia (MA). Therefore, here, we investigated the correlation between MTHFR (C677T, A1298C) and MTRR (A66G) polymorphisms and the risk of MA.

Methods MTHFR (C677T, A1298C) and MTRR (A66G) mutations in 41 newly diagnosed MA patients and 40 controls were detected by real-time PCR.

Results We found that the homozygous mutant 677TT, rather than the heterozygous mutant 677CT, in MA patients is more frequent than that in controls. However, no significant differences were noted in MTHFR (A1298C) and MTRR (A66G) polymorphisms. In combined genotypes, the proportion of homozygous mutations in patients was significantly higher than that in wild and heterozygous mutation types. Furthermore, the clinical examination indices such as mean corpuscular volume, homocysteine, vitamin B12, hemoglobin and red blood cells levels were more abnormal in MA patients with 677TT, 66GG and 66AG genotypes than those in wild genotypes. Finally, a linear correlation between scores and clinical features of MA in scoring system was derived. High risk group exhibited higher prevalence rate of MA and showed more abnormal clinical examination indices than those showed by the low risk group.

Conclusions The proportion of homozygous MTHFR (C677T, A1298G) and MTRR (A66G) mutations has positive correlation with the morbidity of MA in China. The polymorphism scoring system might be useful to assess the risk of MA effectively.

\section{Background}

Megaloblastic anemia (MA) is characterized by the presence of abnormally large red blood cells (RBCs) in the peripheral blood and bone marrow, usually recognized by increased mean corpuscular volume (MCV) [1]. The cause of MA may occur as a result of several fundamentally different mechanisms and demands further clinical and laboratory assessment[2]. One of the most important factors is altered DNA synthesis in all blood cells, usually resulting from vitamin B and/or folic acid deficiencies.

Recent studies found that methylenetetrahydrofolate reductase (MTHFR) and methionine synthase reductase (MTRR) are two critical folate-metabolizing enzymes that play a role in remethylation of homocysteine (Hcy) into methionine as well as in DNA synthesis[3,4,5,6]. The common polymorphisms in MTHFR (C677T and A1298C) and MTRR (A66G) result in reduced MTHFR and MTRR activity in vivo, which in turn leads to impaired folate metabolism and elevated Hcy concentrations. Abnormal folate metabolism may lead to the development of cardiovascular diseases[7], pregnancy complications[8], neural tube defects[9], and MA. Previous reports have indicated that MTHFR (C677T and A1298C) and MTRR (A66G) polymorphisms are associated with an increased risk of the above-mentioned diseases, except MA. 
Therefore, in this study, we detected the genotype of MTHFR and MTRR in MA patients and investigated the association of MTHFR and MTRR polymorphisms with the risk of MA in a cohort of the Chinese population. Based on these results, we established a complete set of scoring system, which will provide an evidence for the risk prediction of MA.

\section{Materials And Methods}

\section{Subjects}

A total of 41 patients and 40 controls were recruited from Shengjing Hospital of China Medical University between March and October 2017. All clinical data were collected on a spreadsheet. MA was identified when peripheral blood examination showed anemia with MCV of $>95 \mathrm{fL}$ [3] accompanied with folic acid or vitamin B12 deficiencies. Approval for the study was received from the Hospital Medical Ethics Committee and all patients involved in the study provided their consent. Patients' information is shown in Table 1.

\section{Genotyping Protocols}

DNA was extracted from EDTA anti-coagulated whole blood from all subjects (controls and patients) using the TIANamp Genomic DNA purification Kit (TIANGEN Biotech, Beijing) and quantified by spectrophotometry. Samples were screened for the C677T and A1298C polymorphism of MTHFR gene and the A66G polymorphism of MTRR gene by ABI 7500 Real Time PCR System with MTHFR and MTRR gene polymorphism detection kit (Yuanqi Bio-Pharmaceutical Co., Ltd, Shanghai). Genotype analysis was performed with allele-specific fluorogenic oligonucleotide probes labeled with the FAM, CY5, and VIC fluorogenic dyes following the manufacturer's instructions.

\section{Polymorphism scoring system of MA}

We developed a polymorphism MA scoring system which was calculated according to MTHFR (C677T, A1298C) and MTRR (A66G) polymorphism to assess the morbidity risk. The scores were assigned as follows: wild type was assigned ' 0 ', heterozygote was assigned ' 1 ', and homozygote was assigned ' 2 ', and the scores were calculated as the sum (MTHFR (C677T) + MTHFR (A1298C) + MTRR (A66G)). We also defined the scores $\geq 3$ as 'high risk', and scores $<3$ as 'low risk'.

\section{Statistical methods}

Data were subjected to statistical analysis and were shown as mean \pm standard deviation (SD). Differences in mean values were analyzed using one-way analysis of variance (ANOVA). Comparisons related to age, sex, red blood cells (RBC), hemoglobin (HGB), MCV, vitamin B12 (B12), and folic acid in clinical characteristics were made by the Independent-Sample T or Mann-Whiney U test. Chi square test 
was performed to assess the Hardy-Weinberg equilibrium among each experimental group and compare the differences among the populations with respect to allele and genotype frequencies. Spearman $r$ test was performed to analyze the correlation between the integration system and the risk of MA. Odds ratios (OR) and $95 \%$ confidence intervals $(\mathrm{Cl})$ were calculated to assess the risk of association; $P<0.05$ was considered statistically significant. All analyses were performed using SPSS13.0 software.

\section{Results}

\section{Study group characteristics and distribution of MTHFR (C677T, A1298C) and MTRR (A66G) polymorphisms}

Characteristics of the patients and controls are shown in Table 1. The HGB, vitamin B12, and plasma folate levels and the RBC count were significantly lower in patients than in controls $(P<0.05)$. Conversely, the MCV and Hcy in patients were obviously higher than those in controls $(P<0.01)$. However, the distribution of other clinical characteristics such as gender and age between patients and controls did not show significant differences $(P>0.05)$.

The distribution of MTHFR (C677T, A1298C) and MTRR (A66G) alleles and genotypes in patients and controls did not deviate from the Hardy-Weinberg equilibrium. As shown in Table 2, TT genotype frequency of MTHFR (C677T) was higher in patients (31.7\%) than in controls $(10.0 \%, P<0.01)$, which was the susceptive genotype for MA occurrence $(\mathrm{OR}=0.171,95 \% \mathrm{Cl}=0.044-0.667)$. The T allele of MTHFR (C677T) was more frequent in patients $(53.7 \%)$ than in healthy subjects $(32.5 \%, P<0.01)$ and it was closely related to $\mathrm{MA}(\mathrm{OR}=0.416,95 \% \mathrm{Cl}=0.220-0.787)$. Moreover, no statistically significant difference was observed in the distribution of the other genotypes, including CT (C677T), AC/CC (A1298C), and AG/GG (A66G) genotypes, between patients and controls (P>0.05). The distribution of C (A1298C) and G (A66G) alleles was not significantly different between patients and controls ( $P>0.05)$. However, in combined genotypes, which were grouped into wild type (CC+AA+AA), heterozygous mutation type $(C C / C T+A A / A C+A A / A G)$, and homozygous mutation type (Table 2), the distribution of these three genotype groups showed significant differences between patients and controls $(P<0.05)$. In addition, the proportion of homozygous mutations in patients was significantly higher and that of heterozygous mutations in patients was significantly lower than those in the normal controls $(P<0.05)$. The frequencies of wild type, heterozygous type, and homozygous type in MA patients were $2.4 \%$ (1/41), 46.3\% (19/41), and $51.2 \%(21 / 41)$, whereas those in controls were $7.5 \%$ (3/40), 70.0\% (28/40), and 22.5\% (9/40), respectively.

\section{Comparison between clinical examination indices of MA and genotypes}


The relationship between clinical features of MA, including vitamin B12, folic acid, MCV, RBC, HGB, and Hcy, and the MTHFR or MTRR genotypes are shown in Table 3. TT genotypes had lower vitamin B12 level, HGB level and RBC count than 677CC and 677CT genotypes of MTHFR (C677T) $(P<0.05)$. In MTRR $(A 66 G)$ mutations, patients with AG genotypes showed lower vitamin B12 and higher MCV levels than those with AA genotypes $(P<0.05)$. Meanwhile, subjects with $66 \mathrm{GG}$ genotypes showed a higher MCV level than those with 66AA genotypes $(P<0.05)$. However, no significant differences in folic acid levels were detected among 677CC, 677CT, and 677TT genotypes of MTHFR (C677T) ( $P>0.05)$. Furthermore, there were no significant differences among the above six clinical examination indices in MTHFR (A1298C) ( $P$ > 0.05).

\section{Comparison of clinical examination indices of MA with polymorphism scoring system}

The risk of MA was evaluated according to the clinical examination indices including MCV, vitamin B12, folic acid, Hcy, and HGB levels and RBC count. The data displayed that the scores were positively correlated with MCV and Hcy concentrations, but negatively correlated with HGB, folic acid, and vitamin B12 concentrations and RBC count (Fig. 1, $P<0.05$ ).

Then the cases were divided into two groups according to the scores-low-risk group and high-risk group. Higher MCV and Hcy levels (Table 4, $P<0.05$ ) and lower HGB, RBC, folic acid, and vitamin B12 levels were noted in the high-risk group than in the low-risk group (Table 4, $P<0.05$ ). Moreover, the high-risk group displayed a higher prevalence rate of MA than that did the low-risk group (36.6\% vs $15.0 \%$, Table 4 , $P<0.05)$.

\section{Discussion}

MA is a type of large-cell hematopoietic anemia characterized by impairment of DNA synthesis in all nucleated cells resulting in distinctive megaloblastic changes and ineffective hematopoiesis in the bone marrow[10]. With diverse etiology, the pathogenesis of MA is generally considered to arise from vitamin B12 and/or folic acid deficiency. However, whether there is susceptibility to genetic inheritance remains to be understood.

It has been reported that the polymorphisms rs1801133 (C677T) on MTHFR and rs1801133 (C677T) on MTHFR lead to a decrease in enzyme activity, causing Hcy accumulation in the body[11]. Hcy-injured endothelial cells and vascular smooth muscle cells induce the activation of procoagulant factors to maintain the body in a hypercoagulable state and promote thrombosis[12]. Polymorphisms of MTHFRand MTRR-related sites can also induce folic acid-related metabolic disorders, which led to the unstable state of DNA chain[13]. Furthermore, the DNA strand fracture and chromosomal rearrangements and separation would lead to MA development [14]. The interference with neural tube closure, results in Down 
syndrome[15], early recurrent spontaneous abortion[16], birth defects, cleft lip and palate, and other diseases in early pregnancy[17].

Given the important role of MTHFR and MTRR in the metabolic pathway of folic acid and vitamin B12, we first described the polymorphisms of MTHFR and MTRR in MA. We found that the homozygous mutant 677TT, rather than the heterozygous mutant $677 \mathrm{CT}$, in MA patients is more frequent than that in controls, suggesting that MTHFR (C677T) gene mutation may be closely related to MA development. However, we could not find a correlation between MTHFR (A1298C) and MTRR (A66G) polymorphisms and etiology of MA, possibly due to the limited number of samples. Besides the effects of single alleles on MA, the combination effects of C677T, A1298C, and A66G were investigated. There were significant differences of genotypic and allelic frequencies among wild type, heterozygous mutation type, and homozygous mutation type between MA patients and controls.

We also found that MTHFR and MTRR gene polymorphisms were relevant to the incidence of MA, inducing differences in correlation indices and morbidity. Vitamin B12 and HGB concentrations and RBC count were lower and MCV and Hcy concentrations were higher in MA patients with TT genotype than in wild genotype, but no significant difference was found in folic acid concentration because of the limited number of cases. Vitamin B12 and MCV levels were also higher in GG and AG genotypes than in AA genotype. Recent studies had shown that MTHFR 677TT genotype is associated with high Hcy and low folic acid concentrations in $\beta$-thalassemia patients[18], and Li concluded that C667T, A1298C, and A66G polymorphisms could elevate the risk of folate deficiency[19]. Lin also reported MA patients with vitamin B12 deficiency and MTHFR (C667T) mutation[20] which was consistent with our results. Based on the above data revealing genotype polymorphism relevant to MA indices, we hypothesized that genotype polymorphism might be involved in MA pathogenesis. The homozygous mutant 677TT[21] can decrease about $50 \%-60 \%$ of MTHFR activity, which might be the ultimate cause of abnormal physiological indices.

Finally, to our knowledge, for the first time, we built a polymorphism scoring system to verify the effectiveness of the genotype in MA. Furthermore, the scoring system manifested that the higher the score, the more HYPERLINK

“../.././AppData/Local/Youdao/Dict/Application/6.3.69.7015/resultui/frame/javascript:void(0);"abnormal clinical examination indices are and the greater the MA risk will be, providing us a new tool to predict the morbidity risk of MA based on the genotype.

\section{Conclusions}

Our results provided a new insight into the correlation between MTHFR (C677T, A1298C) and MTRR (A66G) polymorphisms and the incidence of MA. MTHFR (C677T) is highly correlated with MA, and might participate in its pathogenesis. Our study reveals the pathogenesis of MA at the level of molecular biology, which is innovative and instructive for the prevention and treatment of MA.

\section{Abbreviations}


MTHFR: Methylenetetrahydrofolate Reductase; MTRR: Methionine Synthase Reductase; MA:

Megaloblastic Anemia; MCV: Mean Corpuscular Volume; Hcy: Homocysteine; RBC: Red Blood Cells; HGB: Hemoglobin; B12: Vitamin B12; Cl: Confidence Intervals; OR: Odds Ratios; DNA: Deoxyribonucleic Acid; EDTA: Ethylenediaminetetraacetic Acid; PCR: Polymerase Chain Reaction.

\section{Declarations}

\section{Author's contributions}

Jihong Zhang conceived and designed the study; Shaokun Wang performed the study in the laboratory and conducted data analyses. All authors read and approved the final manuscript.

\section{Funding}

This study was supported by grants from the Natural Science Foundation of Liaoning Province (No. 20170540996).

\section{Ethics approval and consent to participate}

All procedures performed in studies involving human participants were in accordance with the ethical standards of the Ethics Committee of Shengjing Hospital of China Medical University (2017PS127K) and with the 1964 Helsinki declaration and its later amendments or comparable ethical standards. Informed consent was obtained from all individual participants included in the study.

\section{Consent for publication}

Not applicable.

\section{Competing interests}

The authors declare that they have no competing interests.

\section{References}

1. Aslinia F, Mazza JJ, Yale SH. Megaloblastic anemia and other causes of macrocytosis. Clin Med Res. 2006; 4: 236-241. 
2. Green R, Datta Mitra A. Megaloblastic Anemias: Nutritional and Other Causes. Med Clin North Am.2017; 101: 297-317.

3. Vineetha Unnikrishnan, Tarun Kumar Dutta, Bhawana A. Badhe, Zachariah Bobby, Ashish K. Panigrahi. Clinico-aetiologic profile of macrocytic anemias with special reference to megaloblastic anemia. Indian J Hematol Blood Transfus.2008; 24: 155-165.

4. Reilly R, McNulty H, Pentieva K, Strain JJ, Ward M. MTHFR 677TT genotype and disease risk: is there a modulating role for B-vitamins? Proc Nutr Soc. 2014; 73: 47-56.

5. Wu YL, Hu CY, Lu SS, Gong FF, Feng F, Qian ZZ, Ding XX, Yang HY, Sun YH. Association between methylenetetrahydrofolate reductase (MTHFR) C677T/ A1298C polymorphisms and essential hypertension: a systematic review and meta-analysis. Metabolism.2014; 63: 1503-1511.

6. PR Mandaviya, L Stolk, SG Heil. Homocysteine and DNA methylation: A review of animal and human literature. Molecular Genetics \& Metabolism.2014; 113: 243-252.

7. Joseph J, Loscalzo J. Methoxistasis: integrating the roles of homocysteine and folic acid in cardiovascular pathobiology. Nutrients. 2013; 5: 3235-3256.

8. Krikke GG, Grooten IJ, Vrijkotte TG, van Eijsden M, Roseboom TJ, Painter RC. Vitamin B12 and folate status in early pregnancy and cardiometabolic risk factors in the offspring at age 5-6 years: findings from the ABCD multi-ethnic birth cohort. BJOG. 2016; 123: 384-392.

9. Kumiko Ito, Tomoyuki Hanaoka, Naomi Tamura, Seiko Sasaki, Chihiro Miyashita, Atsuko Araki, Sachiko Ito, Hisanori Minakami, Kazutoshi Cho, Toshiaki Endo, Tsuyoshi Baba, Toshinobu Miyamoto, Kazuo Sengoku, Akiko Tamakoshi, Reiko Kishi. Association Between Maternal Serum Folate Concentrations in the First Trimester and the Risk of Birth Defects: The Hokkaido Study of Environment and Children's Health J Epidemiol.2019; 29: 164-171.

10. Lindenbaum J. Status of laboratory testing in the diagnosis of megaloblastic anemia. Blood. 1983; 61: 624-627.

11. Roecklein KA, Scher Al, Smith A, Harris T, Eiriksdottir G, Garcia M, Gudnason V, Launer LJ. Haplotype analysis of the folate-related genes MTHFR, MTRR, and MTR and migraine with aura. Cephalalgia. 2013; 33: 469-482.

12. Hou N, Chen S, Chen F, Jiang M, Zhang J, Yang Y, Zhu B, Bai X, Hu Y, Huang H, Xu C. Association between premature ovarian failure, polymorphisms in MTHFR and MTRR genes and 
serum homocysteine concentration. Reprod Biomed Online. 2016; 32: 407-413.

13. Dokter EM, van Rooij IA, Wijers $\mathrm{CH}$, Groothuismink JM, van der Biezen JJ, Feitz WF, Roeleveld N, van der Zanden LF. Interaction between MTHFR 677C>T and periconceptional folic acid supplementation in the risk of Hypospadias. Birth Defects Res A Clin Mol Teratol. 2016; 106: 275-284.

14. Remacha AF, Souto JC, Rámila E, Perea G, Sarda MP, Fontcuberta J. Enhanced risk of thrombotic disease in patients with acquired vitamin B12 and/or folate deficiency: role of hyperhomocysteinemia. Ann Hematol. 2002; 81: 616-621.

15. Jiajin L, Shuyan C, Ying W, Junxiao C, Xiudi W. Genetic polymorphisms in folate metabolism as risk for Down syndrome in the southern China. J Matern Fetal Neonatal Med. 2019; 32: 2030-2035.

16. Kim SY, Park SY, Choi JW, Kim DJ, Lee SY, Lim JH, Han JY, Ryu HM, Kim MH. Association between MTHFR 1298A>C polymorphism and spontaneous abortion with fetal chromosomal aneuploidy. Am J Reprod Immunol. 2011; 66: 252-258.

17. Zhang $Y$, He X, Xiong X, Chuan J, Zhong L, Chen G, Yu D. The association between maternal methylenetetrahydrofolate reductase $\mathrm{C} 677 \mathrm{~T}$ and $\mathrm{A} 1298 \mathrm{C}$ polymorphism and birth defects and adverse pregnancy outcomes. Prenat Diagn. 2019; 39: 3-9.

18. Liu ZZ, Zhang JT, Liu D, Hao YH, Chang BM, Xie J, Li PZ. Interaction between maternal 5,10methylenetetrahydrofolate reductase C677T and methionine synthase A2756G gene variants to increase the risk of fetal neural tube defects in a Shanxi Han population. Chin Med J (Engl). 2013; 126: 865-869.

19. Abd-Elmawla MA, Rizk SM, Youssry I, Shaheen AA. Impact of Genetic Polymorphism of methylenetetrahydrofolate reductase C677T on Development of Hyperhomocysteinemia and Related Oxidative Changes in Egyptian $\beta$-Thalassemia Major Patients. PLoS One.2016; 11: e0155070.

20. Li WX, Dai SX, Zheng JJ, Liu JQ, Huang JF. Homocysteine Metabolism Gene Polymorphisms (MTHFR C677T, MTHFR A1298C, MTR A2756G and MTRR A66G) Jointly Elevate the Risk of Folate Deficiency. Nutrients. 2015; 7: 6670-6687.

21. Lin HY, Chung CY, Chang CS, Wang ML, Lin JS, Shen MC. Hyperhomocysteinemia, deep vein thrombosis and vitamin B12 deficiency in a metformin-treated diabetic patient. J Formos Med Assoc.2007; 106: 774-778. 
22. Frosst P, Blom HJ, Milos R, Goyette P, Sheppard CA, Matthews RG, Boers GJH, den Heijer M, Kluijtmans LAJ, van den Heuvel LP, Rozen R. A candidate genetic risk factor for vascular disease: a common mutation in methylenetetrahydrofolate reductase. Nat Genet. 1995; 10: 111-113.

\section{Tables}

Table 1. Characteristics of patients and controls

\begin{tabular}{llll}
\hline & Patients $(\mathrm{n}=41)$ & Controls $(\mathrm{n}=40)$ & $\mathrm{P}$ \\
\hline Age $($ years $)$ & $61.56 \pm 17.48$ & $59.23 \pm 12.06$ & $>0.05$ \\
\hline Gender $(\mathrm{M} / \mathrm{F})$ & $20 / 21$ & $18 / 22$ & \\
\hline RBC $\left(\times 10^{12} / \mathrm{L}\right)$ & $1.80 \pm 0.52$ & $4.54 \pm 0.63$ & $<0.05$ \\
\hline $\mathrm{HGB}(\mathrm{g} / \mathrm{L})$ & $71.85 \pm 16.22$ & $130.62 \pm 12.57$ & $<0.05$ \\
\hline $\mathrm{MCV}(\mathrm{fL})$ & $120.20 \pm 9.83$ & $91.11 \pm 6.86$ & $<0.05$ \\
\hline B12 $(\mathrm{pg} / \mathrm{mL})$ & $67.68 \pm 47.96$ & $394.95 \pm 189.13$ & $<0.05$ \\
\hline Hcy $(\mu \mathrm{mol} / \mathrm{L})$ & $13.71 \pm 1.47$ & $9.13 \pm 0.84$ & $<0.05$ \\
\hline Folic $\mathrm{acid}(\mathrm{ng} / \mathrm{mL})$ & $11.19 \pm 4.09$ & $13.37 \pm 5.20$ & $<0.05$ \\
\hline
\end{tabular}


RBC, red blood cells; HGB, hemoglobin; MCV, mean corpuscular volume; B12, vitamin B12; Hcy, homocysteine. 
Page 12/16 
Table 2. Genotypic and allelic frequencies (\%)

\begin{tabular}{|c|c|c|c|c|c|}
\hline Genotypes & $s(n=41)$ & Controls $(n=40)$ & $x^{2}$ & $P$ & OR $(95 \% \mathrm{Cl})$ \\
\hline \multicolumn{6}{|l|}{ MTHFR(C677T) } \\
\hline CC & $10(24.4)$ & $18(45.0)$ & & & 1 \\
\hline CT & $18(43.9)$ & $18(45.0)$ & 1.306 & 0.253 & $0.556(0.202-1.529)$ \\
\hline TT & $13(31.7)$ & $4(10.0)$ & 7.032 & 0.008 & $0.171(0.044-0.667)$ \\
\hline \multicolumn{6}{|l|}{ Alleles } \\
\hline C & $38(46.3)$ & $54(67.5)$ & & & 1 \\
\hline $\mathrm{T}$ & $44(53.7)$ & $26(32.5)$ & 7.388 & 0.007 & $0.416(0.220-0.787)$ \\
\hline \multicolumn{6}{|l|}{ MTHFR(A1298C) } \\
\hline AA & $28(68.3)$ & $25(62.5)$ & & & 1 \\
\hline$A C$ & $7(17.1)$ & $12(30.0)$ & 1.431 & 0.232 & $1.920(0.654-5.636)$ \\
\hline $\mathrm{CC}$ & $6(14.6)$ & $3(7.5)$ & 0.595 & 0.441 & $0.560(0.127-2.478)$ \\
\hline \multicolumn{6}{|l|}{ Alleles } \\
\hline A & $63(76.8)$ & $62(77.5)$ & & & 1 \\
\hline C & $19(23.2)$ & $18(22.5)$ & 0.01 & 0.919 & $0.963(0.462-2.005)$ \\
\hline \multicolumn{6}{|l|}{ MTRR(A66G) } \\
\hline AA & $17(41.5)$ & $23(57.5)$ & & & 1 \\
\hline AG & $20(48.8)$ & $15(37.5)$ & 1.601 & 0.206 & $0.554(0.222-1.387)$ \\
\hline GG & $4(9.7)$ & $2(5.0)$ & 1.228 & 0.268 & $0.370(0.061-2.257)$ \\
\hline \multicolumn{6}{|l|}{ MTRR(A66G) } \\
\hline A & $54(65.9)$ & $61(76.3)$ & & & 1 \\
\hline G & $28(34.1)$ & $19(23.7)$ & 2.125 & 0.145 & $0.601(0.302-1.195)$ \\
\hline Combined genotypes & & & 7.512 & 0.023 & \\
\hline \multicolumn{6}{|l|}{ wild type } \\
\hline$C C+A A+A A$ & $1(2.4)$ & $3(7.5)$ & & & 1 \\
\hline \multicolumn{6}{|l|}{ heterozygous types } \\
\hline $\mathrm{CC} / \mathrm{CT}+\mathrm{AA} / \mathrm{AC}+\mathrm{AA} / \mathrm{AG}$ & $19(46.3)$ & $28(70.0)$ & & 1.000 & $0.491(0.047-5.084)$ \\
\hline homozygous types & $21(51.2)$ & $9(22.5)$ & & & \\
\hline $\mathrm{TT}+\mathrm{AA} / \mathrm{AC}+\mathrm{AA} / \mathrm{AG}$ & $11(26.8)$ & $4(10.0)$ & & 0.117 & $0.121(0.010-1.531)$ \\
\hline $\mathrm{CC} / \mathrm{CT}+\mathrm{CC}+\mathrm{AA} / \mathrm{AG}$ & $6(14.6)$ & $3(7.5)$ & & 0.266 & $0.167(0.012-2.368)$ \\
\hline $\mathrm{CC} / \mathrm{CT}+\mathrm{AA} / \mathrm{AC}+\mathrm{GG}$ & $2(4.9)$ & $2(5.0)$ & & 1.000 & $0.333(0.017-6.654)$ \\
\hline$T T+C C+A A / A G$ & 0 & 0 & & & \\
\hline $\mathrm{TT}+\mathrm{AA} / \mathrm{AC}+\mathrm{GG}$ & $2(4.9)$ & 0 & & 0.400 & $0.333(0.067-1.652)$ \\
\hline $\mathrm{CC} / \mathrm{CT}+\mathrm{CC}+\mathrm{GG}$ & 0 & 0 & & & \\
\hline $\mathrm{TT}+\mathrm{CC}+\mathrm{GG}$ & 0 & 0 & & & \\
\hline
\end{tabular}

Note: $\mathrm{Cl}$, confidence interval; OR, odds ratio. 
Table 3. Comparison of clinical features of MA according to the different genotypes of MTHFR and MTRR

\begin{tabular}{|c|c|c|c|c|c|c|}
\hline Genotypes & Vitamin B12 (pg/mL) & Folic acid (ng/mL) & $\operatorname{MCV}(f L)$ & $\mathrm{RBC}\left(\times 10^{12} / \mathrm{L}\right)$ & HGB (g/L) & $\mathrm{Hcy}(\mu \mathrm{mol} / \mathrm{L})$ \\
\hline \multicolumn{7}{|l|}{ MTHFR C677T } \\
\hline $\mathrm{CC}$ & $244.68 \pm 36.68$ & $12.84 \pm 0.85$ & $101.89 \pm 2.88$ & $3.52 \pm 0.26$ & $109.64 \pm 6.49$ & $9.88 \pm 1.56$ \\
\hline CT & $263.04 \pm 40.99$ & $11.52 \pm 0.57$ & $104.60 \pm 2.56$ & $3.24 \pm 0.26$ & $101.69 \pm 5.47$ & $10.42 \pm 1.07$ \\
\hline TT & $132.51 \pm 32.02 *$ & $10.68 \pm 0.94$ & $112.42 \pm 4.30 *$ & $2.34 \pm 0.30 *$ & $86.76 \pm 7.39 *$ & $16.20 \pm 2.21^{\star}$ \\
\hline \multicolumn{7}{|c|}{ MTHFR A1298C } \\
\hline AA & $220.23 \pm 28.41$ & $11.76 \pm 0.51$ & $105.74 \pm 2.22$ & $3.06 \pm 0.22$ & $98.60 \pm 4.76$ & $11.43 \pm 1.03$ \\
\hline$A C$ & $286.81 \pm 57.07$ & $12.95 \pm 1.01$ & $101.77 \pm 3.50$ & $3.53 \pm 0.28$ & $112.94 \pm 6.80$ & $9.64 \pm 1.55$ \\
\hline $\mathrm{CC}$ & $161.25 \pm 48.88$ & $9.65 \pm 1.31$ & $110.18 \pm 5.87$ & $2.85 \pm 0.47$ & $92.67 \pm 10.52$ & $15.37 \pm 4.03$ \\
\hline \multicolumn{7}{|l|}{ MTRR A66G } \\
\hline AA & $275.52 \pm 34.85$ & $11.44 \pm 0.62$ & $100.38 \pm 2.12$ & $3.40 \pm 0.25$ & $105.70 \pm 5.40$ & $10.63 \pm 1.40$ \\
\hline$A G$ & $175.78 \pm 34.12^{\star}$ & $12.45 \pm 0.62$ & $109.51 \pm 2.99 *$ & $2.94 \pm 0.24$ & $97.88 \pm 5.51$ & $11.38 \pm 1.11$ \\
\hline GG & $233.30 \pm 71.65$ & $10.45 \pm 2.29$ & $113.65 \pm 5.98 *$ & $2.71 \pm 0.56$ & $92.00 \pm 14.71$ & $17.34 \pm 3.36$ \\
\hline
\end{tabular}

$\star, P<0.05$, compared to wild type 
Table 4. Comparison of clinical features and morbidity according to the scoring system

\begin{tabular}{llll}
\hline Genotypes & low risk $(\mathrm{n}=60)$ & high risk $(\mathrm{n}=21)$ & P value \\
\hline $\mathrm{RBC}\left(\times 10^{12} / \mathrm{L}\right)$ & $3.36 \pm 1.50$ & $2.54 \pm 1.31$ & 0.029 \\
\hline $\mathrm{HGB}(\mathrm{g} / \mathrm{L})$ & $105.42 \pm 34.20$ & $87.71 \pm 29.18$ & 0.038 \\
$\mathrm{MCV}(\mathrm{fL})$ & $103.15 \pm 16.54$ & $113.50 \pm 15.78$ & 0.015 \\
\hline $\mathrm{B} 12(\mathrm{pg} / \mathrm{mL})$ & $262.63 \pm 223.49$ & $134.06 \pm 144.20$ & 0.004 \\
\hline $\mathrm{Hcy}(\mu \mathrm{mol} / \mathrm{L})$ & $10.25 \pm 7.40$ & $14.86 \pm 8.77$ & 0.022 \\
Folic acid $(\mathrm{ng} / \mathrm{mL})$ & $12.90 \pm 4.85$ & $10.45 \pm 4.12$ & 0.043 \\
\hline healthy people & $34(85.0 \%)$ & $6(15.0 \%)$ & 0.028 \\
\hline MA patients & $26(63.4 \%)$ & $15(36.6 \%)$ & \\
\hline
\end{tabular}

RBC, red blood cells; HGB, hemoglobin; MCV, mean corpuscular volume; B12, vitamin B12; Hcy, homocysteine.

\section{Figures}


A

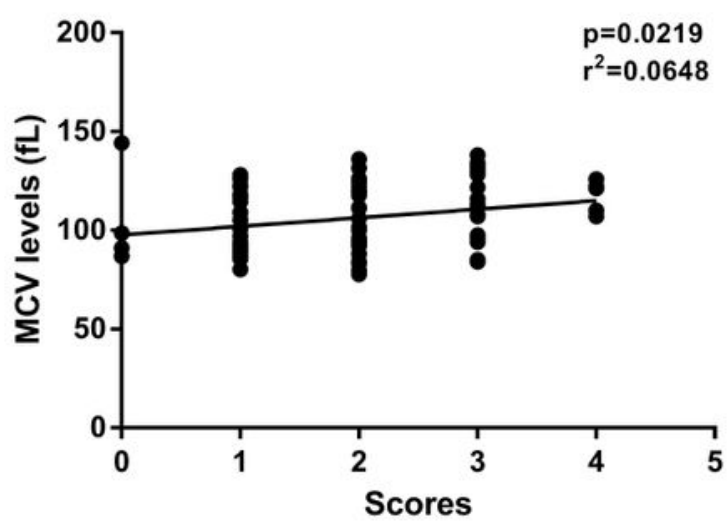

C
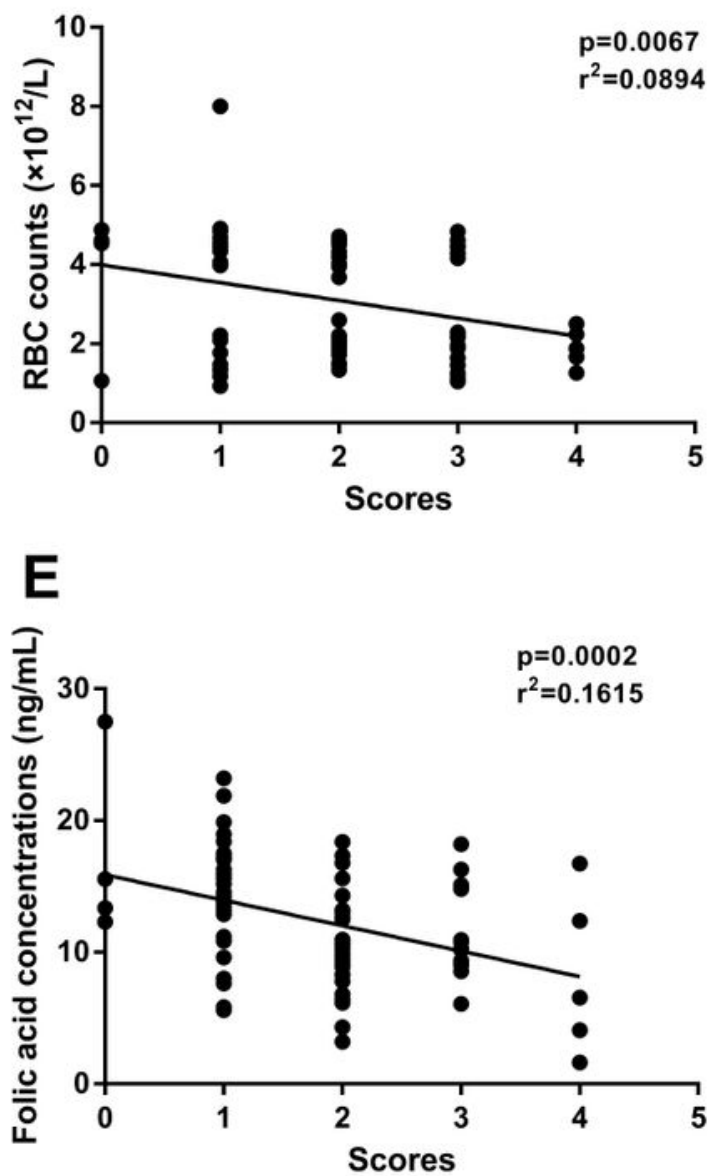

B

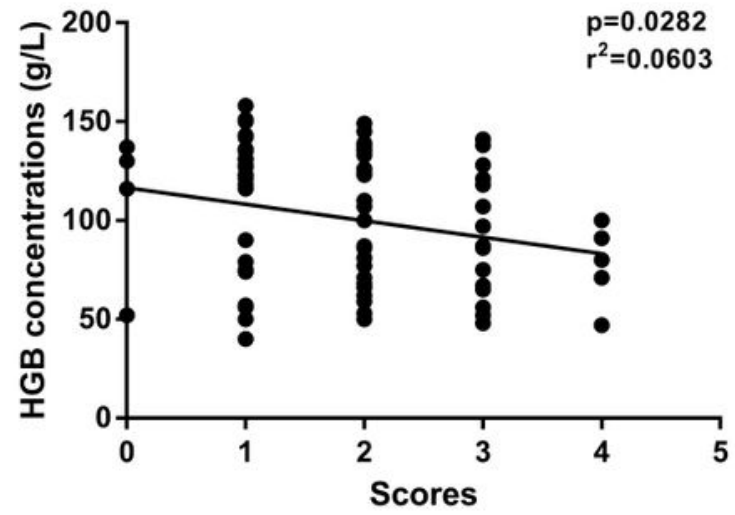

D

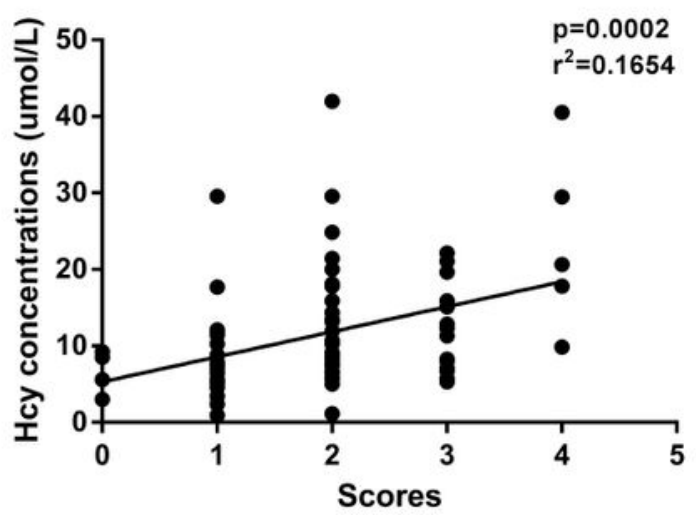

$\mathbf{F}$

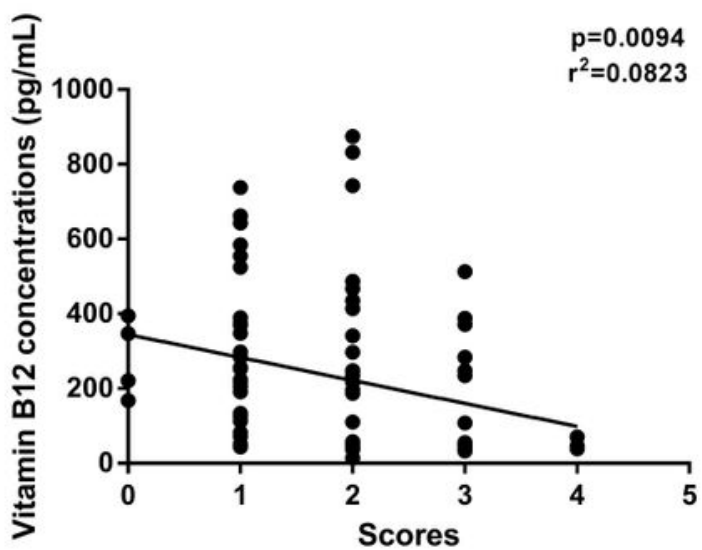

Figure 1

The correlation between integration system and the risk of MA. (A) The scores were positively correlated with MCV levels. (B) The scores were negatively correlated with HGB concentrations. (C) The scores were negatively correlated with RBC count. (D) The scores were positively correlated with Hcy concentrations. (E) The scores were negatively correlated with folic acid concentrations. (F) The scores were negatively correlated with vitamin B12 concentrations. 